\title{
PHÁRMAKON \\ DO COMBATE DA \\ ENFERMIDADE \\ À INVENÇÃO DA IMORTALIDADE
}

COORD.

CAROLINA ESTEVES SOARES

CAROLINA RUFINO

FRANCISCO ISAAC

JOSÉ MALHEIRO MAGALHÃES 
Coordenação: Carolina Esteves Soares, Carolina Rufino, Francisco Isaac, José Malheiro Magalhães Design gráfico: Helena Lobo Design | www.hldesign.pt Imagem da capa: Pormenor do laboratório de Análises Clínicas (c. 1930). Fotografia de Florentino Franco (CLEPUL)

Edição: CITCEM - Centro de Investigação Transdisciplinar Cultura, Espaço e Memória

Via Panorâmica, s/n | 4150-564 Porto | www.citcem.org | citcem@letras.up.pt ISBN: 978-989-8970-07-7

DOI: https://doi.org/10.21747/978-989-8970-07-7/pha

Porto, dezembro de 2018

Produção: www.decadadaspalavras.com

Impressão e acabamento: Clássica, Artes Gráficas. Porto

Trabalho cofinanciado pelo Fundo Europeu de Desenvolvimento Regional (FEDER) através do COMPETE 2020 Programa Operacional Competitividade e Internacionalização (POCI) e por fundos nacionais através da FCT, no âmbito do projeto POCI-01-0145-FEDER-007460. 


\section{SUMÁRIO}

NOTA DE ABERTURA

Carolina Esteves Soares, Carolina Rufino, Francisco Isaac, José Malheiro Magalhães

INTRODUÇÃO

Augusto Moutinho Borges

\section{PRÁTICAS CURATIVAS NO ANTIGO EGIPTO}

Práticas Curativas no Egipto antigo: A Incubação de Sonhos no Sanatorium do Templo de Hathor, em Dendera

José das Candeias Sales

Objectos para a saúde física e mental do antigo Egipto

Telo Ferreira Canhão

II. SAÚDE, ALIMENTAÇÃO E SEXUALIDADE NA ANTIGUIDADE

O tratado De tuenda sanitate praecepta de Plutarco: saúde e alimentação

Dois sexos, uma natureza? $\mathrm{O}$ discurso sobre o corpo feminino nos tratados de medicina antiga

Uma leitura «médica» da homossexualidade no Corpus Aristotelicum (Pr. 4.26-27)

Nuno Simões Rodrigues

Anticonceptivos, cocodrilos y estorninos. Experimentación, conocimiento y falsificación en la ginecología romana

Patricia González Gutiérrez

\section{SAÚDE NA EPIGRAFIA ROMANA}

Acerca do culto às divindades salutíferas na Lusitânia ocidental

José d'Encarnação

Médicos, Arqueólogos e Epigrafistas na segunda metade do século XIX

Pedro Marques ${ }^{\dagger}$

IV. SAÚDE NO MUNDO MEDIEVAL

Nascer e morrer, em Portugal, na Idade Média

Ana Rodrigues Oliveira

Prescrições sobre a alimentação nos penitenciais moçárabes (sécs. IX-XI)

Mário de Gouveia

Da Farmacopeia à Alquimia... e volta

Pedro Gomes Barbosa 


\section{PRAGAS, EPIDEMIAS E PESTES}

Os feridos no terramoto de 1755 em Lisboa

Amélia Ferreira, Alexandra Esteves, Amélia Simões Figueiredo

Contra o mal de gerações - Legislação e práticas sanitárias no Porto na segunda metade do século XVI e século XVII

Catarina Encarnação Pereira

A pneumónica em Montemor-o-Novo

Teresa Fonseca

VI. ENTRE A DOENÇA E CURA: OS HOSPITAIS, AS SUAS EQUIPAS E EQUIPAMENTOS Ana Catarina Necho

Escravos e Saúde

Jorge Fonseca

Alguns aspetos do contexto assistencial do Hospital da Irmandade dos Clérigos Pobres do Porto entre o último quartel do século XVIII e meados do século XIX

António Miguel Santos

As transformações no Hospital da Santa Casa da Misericórdia de Porto de Mós, na

3. ${ }^{\mathrm{a}}$ década do século $\mathrm{XX}$

Kevin Carreira Soares, Maria Alexandra Carlos

A enfermagem e a inauguração do Hospital de Alienados do Conde de Ferreira (1883)

Analisa Candeias, Luís Sá, Alexandra Esteves

Evolução das radiações em saúde: modificações técnicas e relevância médico-científica

Joana da Fonseca e Oliveira, Sérgio Ricardo Joaquim Valente

A ambulância da Cruz Vermelha em Moçambique (1916-1918)

Helena da Silva

\section{A TRANSFORMAÇÃO DOS ESPAÇOS COMO POTENCIADORES DA SAÚDE E BEM-ESTAR}

Mobiliário assistencial nos hospitais militares em Portugal do último quartel do século XVIII ao século XIX

Augusto Moutinho Borges

The challenge of living in Belgrade 1918-1941: housing, disease and malnourishment

Nikola Samardžić, Vladimir Abramović, Maja Vasiljević, Haris Dajč

As cidades como espaços de transformação da natalidade na Época Contemporânea: influência da mobilidade geográfica na regulação da capacidade reprodutiva das populações

Rui Leandro Maia

Cidade Termal, Cidade (I)Mortal?

Jorge Mangorrinha

Entre a vida e a morte: a importância dos registos cemiteriais para o estudo de moléstias no cemitério municipal de Loures (1890-1900)

Ana Paula de Sousa Assunção

Quinhentos anos de marcos históricos de saúde mental nos Açores e na Madeira 
A ergoterapia nos hospitais de alienados em Portugal (1848-1910): mito ou realidade?

Sérgio Tenreiro Gomes

VIII. LITERATURA, FILOSOFIA E SAÚDE

Saúde e enfermidade em um manuscrito jesuítico inédito: o Paraguay Natural Ilustrado, do padre jesuíta José Sánchez Labrador (1771-1776)

Eliane Cristina Deckmann Fleck

O corpo em excesso: uma leitura de $A$ Farsa

Vanda Figueiredo

Melancolia, histeria e o carácter opaco do ser humano em Søren Kierkegaard

Sara Carvalhais de Oliveira

O silêncio (de Maina Mendes) — a literatura como ponto de rutura; conciliação com a deformação

Susana Vieira

Da esfera da autonomia à da vida e desta à morte: sobre o percurso da doença em Naissance de la Clinique, de Michel Foucault

Mariana Gomes da Costa

Saúde, Prazer e os seus contrários na República IX de Platão

Samuel Carvalhais de Oliveira

Cura - Entre Epicuro e Ricoeur - algumas notas de filosofia

Rui Maia Rego 


\title{
DOIS SEXOS, UMA NATUREZA? O DISCURSO SOBRE O CORPO FEMININO NOS TRATADOS DE MEDICINA ANTIGA
}

\author{
CRISTINA SANTOS PINHEIRO*
}

Na sua obra publicada em 1990, com o título Making Sex: Body and Gender from the Greeks to Freud, Thomas Laqueur defendia a tese de que desde os Gregos antigos e até um momento indeterminado do século XVIII, em que se teria inventado a noção de sexo, as mulheres tinham sido consideradas uma versão inferior dos homens e não um sexo em si mesmas. Este paradigma, que se teria prolongado de forma mais ou menos coerente por cerca de dois milénios e a que Laqueur deu o nome de «one-sex model» opor-se-ia a um paradigma baseado na diferenciação absoluta dos sexos. Em Making Sex, dividia-se, deste modo, a história do corpo no mundo ocidental em duas etapas: na primeira, cujo fundamento eram alguns passos do tratado De usu partium de Galeno, o corpo masculino seria entendido como a norma, sendo que o corpo das mulheres era compreendido como em tudo semelhante ao dos homens, menos nos órgãos genitais, interiores nas mulheres, exteriores nos homens mas essencialmente os mesmos, criando algo a que poderíamos designar de um homem invertido ou um homem virado do avesso; durante séculos e por influência galénica, teria existido na humanidade apenas um modelo de corpo humano - o masculino - e o corpo das mulheres não seria mais do que um desvio deste modelo que se configuraria como a norma. Na segunda fase, depois do século XVIII, ter-se-ia criado a consciência de que a diferença sexual é mais abrangente e rígida.

* Universidade da Madeira e Centro de Estudos Clássicos da Faculdade de Letras da Universidade de Lisboa; Professora auxiliar; cristinap@staff.uma.pt. Este artigo segue o Acordo Ortográfico de 1945. 
Já muito se escreveu sobre estes modelos isomórfico e dimórfico de Laqueur e mesmo na área dos Estudos Clássicos e da História Medieval foram demonstradas as limitações desta teoria ${ }^{1}$, pelo que não nos deteremos nela. Serve esta referência apenas para contextualizar a análise de um conjunto de textos antigos, na sua maioria escritos em Grego, mas que tiveram seguidores vários na medicina romana, em que se aborda precisamente o tema da diferenciação sexual. Este conjunto de obras abranje um intervalo temporal que começa com os tratados hipocráticos (os mais antigos remontarão ao século $\mathrm{V}$ a. $\mathrm{C}^{2}$ ), e que termina com os textos de Galeno, compostos já nos séculos II-III da nossa era (a data da morte de Galeno terá sido cerca de 217 d. C.). Entre uns e os outros, situam-se autores como Aristóteles (384-322 a. C.), Herófilo de Alexandria ou Sorano de Éfeso, e as múltiplas versões, revisões e traduções que se fizeram das obras destes autores, em especial da obra biológica de Aristóteles e do tratado sobre as doenças das mulheres da autoria de Sorano.

Estes textos foram, durante séculos, a base de noções aparentemente discordantes acerca do funcionamento do corpo feminino, em especial no que concerne à sua função reprodutora, e fundamentaram abordagens divergentes no entendimento da diferença sexual construída hierarquicamente, tanto a nível médico, como cultural. É necessário, porém, lembrar que o conhecimento do corpo humano - seja masculino ou feminino - é, na época, limitado e que, por falta de meios tecnológicos e por restrições de ordem cultural, como as relativas à manipulação do corpo feminino ou a dissecção de cadáveres, estes autores conhecem mal o interior do corpo humano e muitos dos processos que aí se desenvolvem. Em consequência, tenta-se compreendê-los de forma indirecta através da observação da carcaça de animais e com frequência descreve-se recorrendo a metáforas e analogias várias. As mais importantes e frequentes neste contexto serão talvez a comparação do feto in utero a uma planta ou a analogia entre o útero e as suas partes a um vaso. $O$ corpo das mulheres assume-se como um desafio e alguns processos interiores, como os relacionados com a procriação, são para estes autores difíceis de entender e de explicar. Relembre-se que o espermatozóide é uma descoberta de Antonie van Leeuwenhoek, em finais do século XVII, e que o óvulo humano foi identificado já em 1928, depois de em 1905 se ter reconhecido, então

\footnotetext{
${ }^{1}$ Vejam-se, a título de exemplo, STOLBERG, 2003; PARK, 2010 ou KING, 2013.

${ }^{2} \mathrm{O}$ Corpo Hipocrático é uma colectânea de cerca de sessenta tratados de origens, autores e épocas diversas, reunidos provavelmente em Alexandria no século III ou II a. C. Destes, dez exploram temáticas relacionadas com a ginecologia ou com a embriologia. São: os dois livros do tratado De affectibus mulierum (Sobre as doenças femininas), em Grego Gynaikeia; De sterilitate (Sobre a esterilidade), que aparece na tradição manuscrita como o terceiro livro dos Gynaikeia; De natura muliebri (Sobre a natureza feminina); De semine (Sobre a semente), De natura pueri (Sobre a natureza da criança), De septimestri partu (Sobre o parto de sete meses), De octimestri partu (Sobre o parto de oito meses), De uirginum morbis (Sobre as doenças das jovens), De foetus exsectione (Sobre a excisão do feto), De superfetatione (Sobre a superfetação). Às informações veiculadas nestes tratados podem juntar-se outras em tratados de natureza geral, como as secções acerca das doenças femininas de Aforismos (Aph.) e de Lugares no Homem (Loc.). Sobre os problemas de autoria dos tratados hipocráticos, cf. NUTTON, 2004: 60ss.
} 
ainda de forma incipiente, o papel das hormonas ${ }^{3}$. Trata-se, pois, de descobertas extremamente recentes e, por esta razão, questões como a contribuição feminina para a concepção, para a transmissão de características hereditárias ou para a definição do sexo da criança mantêm-se sem resposta cabal até muito tarde.

Nos tratados hipocráticos, o corpo das mulheres é entendido como um corpo completamente diferente do do homem e essa diferença é global. Como afirma o autor do tratado De mulierum affectibus, as mulheres têm doenças próprias que os médicos não conseguem curar porque as tratam como se fossem doenças de homens e, refere, "o tratamento das doenças das mulheres difere em muito do das doenças dos homens» $(1.62)^{4}$. Esta diferença é profunda e, como se disse, abrange o corpo todo. Lê-se no mesmo tratado que «a mulher tem a carne menos densa e mais débil do que o homem e, por esta razão, o corpo da mulher elimina uma maior quantidade de humor e mais rapidamente do que o do homem.» $\left(1.1^{5}\right)$. Diz-se também que as mulheres têm o sangue mais quente do que os homens e que, por essa razão, são mais quentes do que estes $^{6}$. O corpo feminino é um corpo poroso, pouco firme e com textura esponjosa, que absorve e retém mais líquidos e torna a mulher um ser húmido ${ }^{7}$. As antíteses quente/ frio, húmido/seco, e poroso/firme são - e serão, aliás até muito tarde, — pontos cardeais na exploração da diferença sexual nos textos médicos.

Não se refere nos tratados hipocráticos, todavia, qualquer tipo de valorização ou desvalorização. Não se diz se a natureza firme, seca e fria dos homens é melhor - em qualquer sentido que seja - do que a das mulheres. O que se diz, sim, é que o difícil equilíbrio dos humores, em especial do sangue, torna as mulheres vulneráveis a determinados tipos de patologia relacionados com a retenção ou com os movimentos anormais dos fluxos. O útero, que é, nestes textos, a marca por excelência da diferença

\footnotetext{
${ }^{3}$ Karl Ernst von Baer descobriu o óvulo dos mamíferos em 1827, e Edgar Allen o óvulo humano em 1928.

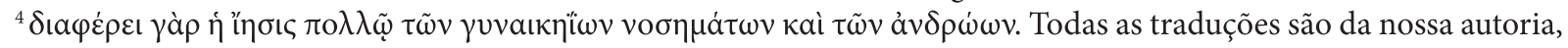
excepto se dada outra indicação. As edições dos textos gregos são, salvo indicação em contrário, as recolhidas no Thesaurus Linguae Graecae.

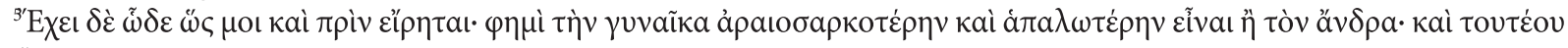

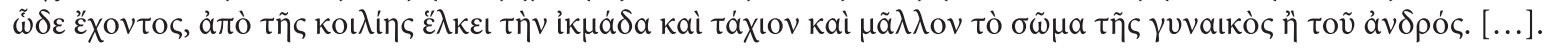

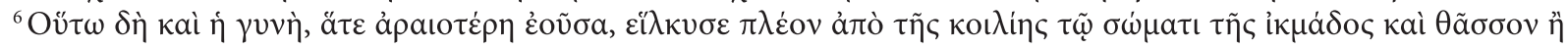

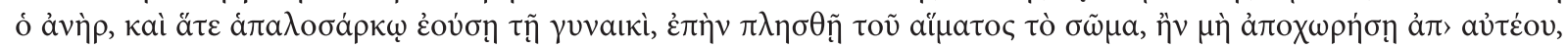

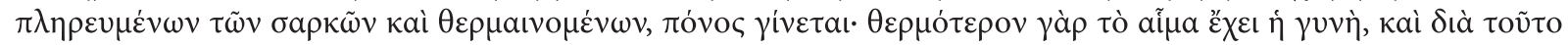

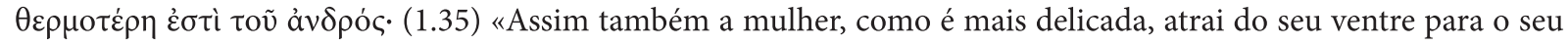
corpo mais humor e mais rapidamente do que o homem. E porque a carne da mulher é delicada, quando o seu corpo se encheu de sangue, se não o retira dele, por se encherem e se tornarem mais quentes as suas carnes, gera-se a dor. É que a mulher tem o sangue mais quente e por esta razão ela é mais quente do que o homem».

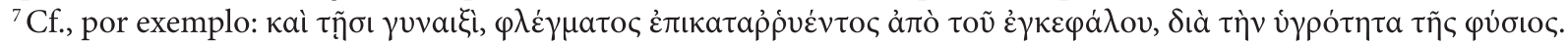
(Aer. 10.30) «e também as mulheres, por lhes descer a fleuma do cérebro, por causa da sua natureza húmida [correm

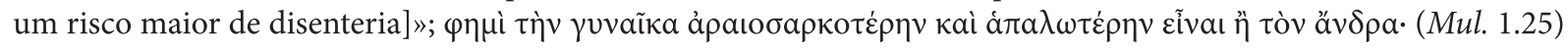

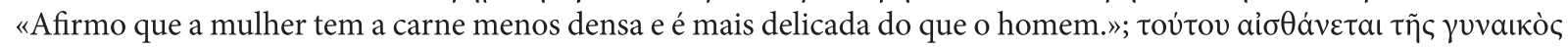

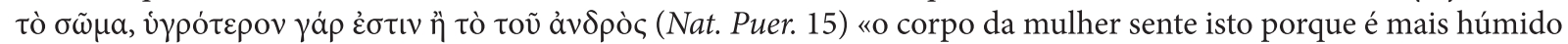

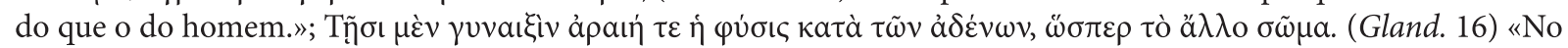
que diz respeito às glândulas, as mulheres têm uma natureza pouco densa como acontece com o resto do corpo».
} 
feminina, é «a causa de todas as doenças» das mulheres ${ }^{8}$, especialmente devido à possibilidade de se movimentar praticamente sem limites através do corpo, exercendo pressão nos órgãos para junto dos quais se deslocaria. Esta teoria hipocrática do útero volante, móvel ou errante, manteve-se até muito tarde, mesmo depois de Herófilo ter identificado os ligamentos do útero que tornam impossíveis estas suas supostas deambulações.

A distinção entre os sexos é profunda e remonta à própria concepção. Parece muito antiga e é frequente a associação do masculino ao lado direito e do feminino ao lado esquerdo. Esta dicotomia está presente na tabela dos opostos pitagóricos ${ }^{9}$ e é desenvolvida pelos autores hipocráticos e também por Aristóteles e por Sorano que, ainda assim, admitem que não é uma relação absoluta. Afirma-se nestes textos que o testículo do lado esquerdo gera mulheres, o do lado direito homens; o feto feminino desenvolve-se no lado esquerdo do útero, o masculino no lado direito. Se a mulher está grávida de um rapaz, o seio direito está maior do que o esquerdo; se espera uma menina terá mais volume o direito. $\mathrm{O}$ sexo do feto é discernível também no aspecto da mãe: uma mulher grávida de uma menina tem uma aparência mais doentia do que a de um rapaz. Isto deve-se também ao facto de o feto do sexo masculino se movimentar mais no ventre materno, fazendo assim com que a mãe se exercite mais (mesmo involuntariamente) e se sinta melhor.

Muitas das categorias que servem de base à caracterização do corpo feminino são expressas no grau comparativo: mais húmido, mais quente, mais esponjoso, mais delicado. No entanto, parece-nos, não se estabelece nos tratados hipocráticos nenhum tipo de hierarquização, no sentido de se defender que, por exemplo, ser mais quente é melhor, mais conveniente ou mais adequado do que ser mais frio. Estas categorias servem, aliás, para explicar não apenas as diferenças entre homens e mulheres, mas também as diferenças entre as idades da vida humana. Mulheres muito brancas, afirma-se na mesma obra, são mais húmidas que as mulheres de pele mais escura; as mais jovens mais húmidas do que as mais velhas (Mul. 111; Nat. Mul. 1). As crianças são mais húmidas e mais quentes do que os idosos.

É em especial na obra biológica de Aristóteles que a comparação se torna sistemática ${ }^{10}$. Atente-se, todavia, no facto de nos tratados biológicos de Aristóteles o ser humano ser

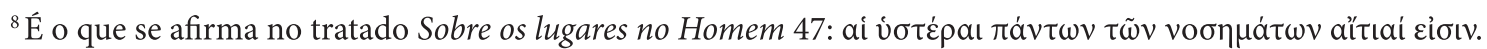

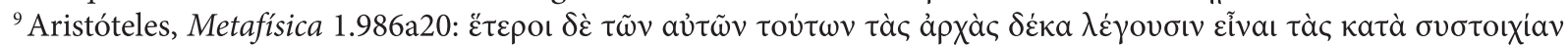

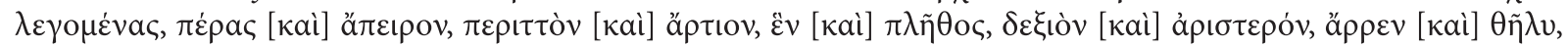

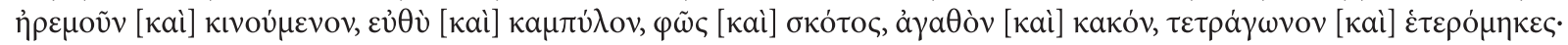
«Outros da mesma escola (i. e. os Pitagóricos) defendem que existem dez princípios, que enunciam numa série de paralelos: limitado e ilimitado; par e ímpar; unidade e pluralidade; direito e esquerdo; macho e fêmea; parado e em movimento; recto e recurvado; luz e escuridão; bem e mal; quadrado e oblongo».

${ }^{10}$ Integram a obra biológica de Aristóteles os tratados História dos Animais (HA), Partes dos Animais (PA) e Geração dos Animais (GA). Não sendo tratados médicos, dão-nos, ainda assim, uma perspectiva essencial sobre a distinção dos sexos na Antiguidade, perspectiva que em muito influenciou a cultura ocidental.
} 
apenas um dos elementos em análise e de as teorias propostas abrangerem categorias mais vastas - com frequência consideradas em oposição, como, por exemplo, os animais e as plantas ou os animais vivíparos e os ovíparos. Em Geração dos Animais $(G A)$, provavelmente a obra que mais se cita para mostrar as ideias aristotélicas sobre as diferenças entre os sexos, afirma-se que macho e fêmea são os dois princípios da reprodução nos seres que têm esta distinção, que o macho é um ser que gera em outro e a fêmea o que gera em si mesmo, que o macho detém o princípio do movimento e da geração e a fêmea o princípio material ${ }^{11}$. Na concepção aristotélica da reprodução, a semente masculina une-se à feminina que é o sangue menstrual. Uma proporciona a forma e o movimento, a outra o corpo e a matéria ( $G A 729 \mathrm{a} 10^{12}$ ). Uma vez que a fêmea é mais fria, não tem a capacidade de concluir o processo de pepsis do alimento que o transformará em semente. A palavra pepsis, que normalmente se traduz por «digestão», é, no entanto, entendida pelos autores antigos como um processo de cozimento dos alimentos no estômago e também no fígado por acção do calor ${ }^{13}$. No macho, este processo transforma o nutrimento primeiro em sangue, depois em sémen. Mas na fêmea, a ausência de calor suficiente para «cozer» o nutrimento impede que o processo seja levado a termo (GA 728a19). Por esta «incapacidade» ( $\alpha \delta v v \alpha \mu i \alpha)$, que é um traço que distingue macho e fêmea, a semente feminina é um produto intermédio entre o sangue e o sémen: o sangue menstrual (GA 765b.10). O fluxo menstrual que nos tratados hipocráticos tem a função de nutrir o feto, assume em Aristóteles e até muito tarde a função de providenciar a matéria à qual o sémen masculino dá forma, como o coalho faz ao leite no fabrico de queijo ( $\left.G A 729 \mathrm{a} 10^{14}\right)$. É um estado intermédio de um processo que só no macho se realiza por completo.

Duas das frases mais citadas acerca da diferenciação sexual, fora de contexto a maioria das vezes, referem-se precisamente a esta distinção entre as propriedades da semente masculina e as da feminina. Lê-se em Geração dos Animais 728a18:

\footnotetext{
${ }^{11}$ Veja-se, por exemplo, 716a10-15.

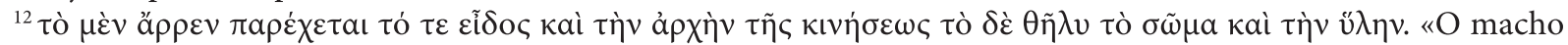

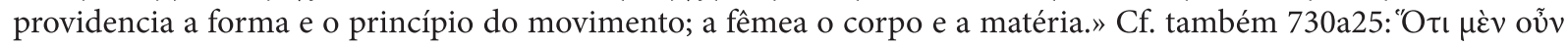

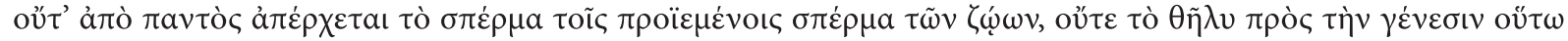

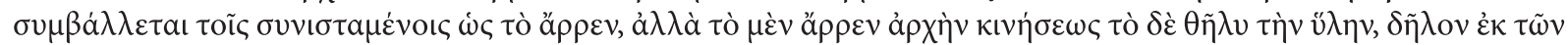

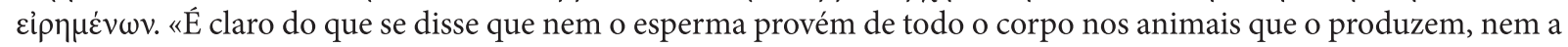
fêmea contribui para a geração da mesma forma que o macho para a formação, mas o macho providencia o princípio do movimento, a fêmea a matéria».

${ }^{13}$ Uma tradução mais fiel seria «cocção». Significa também «amadurecimento».

${ }^{14}$ Ainda no séc. I d. C., Plínio retomava esta imagem: sed tales non gignunt, quando haec est generando homini materia, germine e maribus coaguli modo hoc in sese glomerante, quod deinde tempore ipso animatur corporaturque. (Nat. 7.66) «Estas [i. e. mulheres que não menstruam] porém não concebem, porque esta é a matéria de que se gera um ser humano. A semente masculina, actuando como coalho, faz com que o sangue menstrual se torne compacto e, passado algum tempo, ganhe vida e tome forma corpórea».
} 


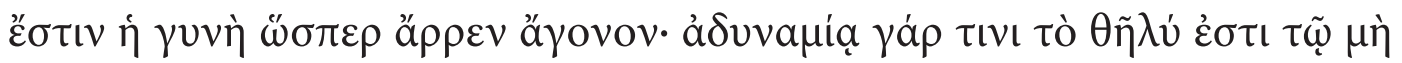

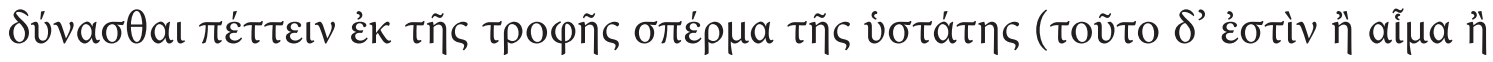

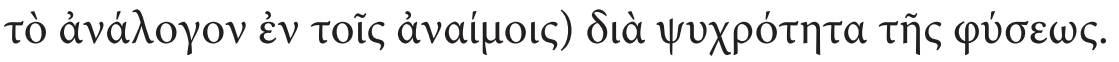

A mulher é como um macho infértil: pois é fêmea por uma certa incapacidade que é não ser capaz de produzir esperma do último estádio do nutrimento (isto é, ou sangue ou o análogo nos seres não sanguíneos) devido à frieza da sua natureza.

E em 737a:

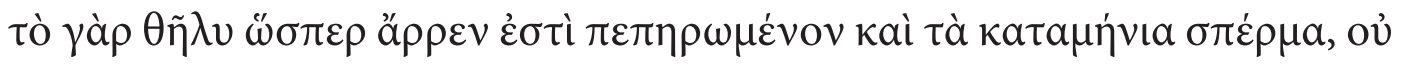

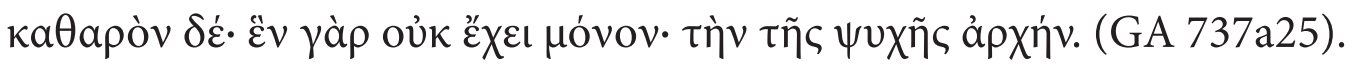

A fêmea é como um macho mutilado. E a menstruação é uma semente, mas não pura, pois nela não existe apenas um elemento: o princípio da alma.

Note-se que em ambas as frases se afirma que a mulher, no primeiro excerto, a fêmea no segundo, é como um macho infértil ou um macho mutilado, criando assim uma associação entre o sexo feminino e as limitações relacionadas com o papel que Aristóteles lhe confere na reprodução. A identificação entre a mulher e um homem mutilado ou um homem estéril é parcial, uma vez que diz apenas respeito ao processo reprodutivo. Ainda assim, a mulher como as fêmeas de todos os animais, é mais débil, mais delicada, tem o corpo menor, é mais fria (726b34, 727a15-20, 728a21, 766a1).

Se existe entre os autores antigos uma perspectiva unívoca e hierarquizada dos sexos, em que a fêmea é definida como deficiente, limitada ou aquém da norma, essa perspectiva é aristotélica. Nos autores dos tratados hipocráticos de temática ginecológica ou embriológica, fala-se de uma semente masculina que se une, se mistura com uma semente feminina. Em Aristóteles, estabelece-se uma desigualdade permanente, a nível fisiológico e, inclusive, a nível psicológico e social. Em História dos Animais 608a33-609b15, esta desigualdade é perceptível em características mentais: a mulher é mais sensível, mais chorosa, mais ciumenta, mais queixosa, mais dada às injúrias e às agressões, desespera mais facilmente do que o homem ${ }^{15}$.

A tradição de descrever a natureza feminina em oposição à masculina dá um passo adiante com Herófilo, que terá vivido em Alexandria no século IV-III a. C., e que é reconhecido como o precursor dos estudos de anatomia. Perdeu-se toda a

\footnotetext{
${ }^{15} \mathrm{~A}$ diferença entre os sexos na obra de Aristóteles é a tal ponto rígida que está na base de alguns dos erros anatómicos mais conhecidos do Estagirita, como a afirmação de que os homens têm mais dentes (HA 501b19-21) e mais suturas cranianas do que as mulheres (PA 653a29-b13; HA 516a15-20). Diga-se, todavia, que para Aristóteles o tamanho do cérebro não está relacionado com as capacidades intelectivas de homens e mulheres, como erroneamente se afirma, uma vez que na visão aristotélica a razão reside no coração e não no cérebro. Para uma justificação destes erros, veja-se MAYEW, 2004: 72-75; 81-86.
} 
sua obra, conhecida apenas pelas referências de autores posteriores como Sorano ou Galeno. Ao contrário dos outros autores sobre os quais se debruça este estudo, Herófilo praticou dissecções em cadáveres e mesmo em seres humanos vivos ${ }^{16}$. No que concerne à anatomia feminina, Herófilo identificou as trompas de Falópio e os ovários, que são desconhecidos para os autores do Corpo Hipocrático e para Aristóteles. A estes

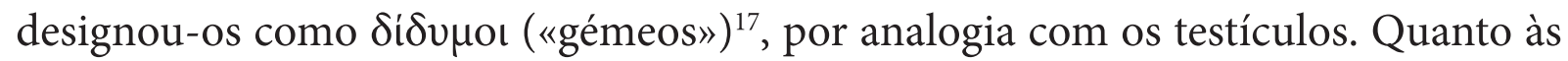
trompas de Falópio, errou ao concluir que ligavam os ovários à bexiga e não ao útero e, por este motivo, não entendeu a contribuição feminina para a procriação ${ }^{18}$. Descreveu os ligamentos do útero, as alterações do colo do útero, os vasos sanguíneos do aparelho reprodutor feminino e do cordão umbilical, o que constitui, como diz Von Standen na sua obra Herophilus: the art of medicine in early Alexandria: edition, translation, and essays ${ }^{19}$, «an increment of scientific progress no less admirable than the detailed differentiations he introduced into the anatomy of the male reproductive organs».

De Sorano de Éfeso, um autor de origem grega do século I d. C., que exerceu medicina em Roma nos principados de Trajano e Adriano, chegou-nos um manual em quatro livros dedicado às parteiras em que Sorano apresenta uma síntese da medicina do seu tempo e comenta muitas das teorias dos autores que o precederam. Este manual, com o título Gynaikeia ${ }^{20}$, é uma fonte importante acerca do pensamento de autores cuja obra se perdeu, como é o caso de Herófilo. Em 3.1, numa secção em que se questiona a existência de doenças específicas das mulheres, Sorano apresenta uma síntese das teses defendidas por outros autores. Sabemos por Sorano que Herófilo defendia que o útero era feito da mesma matéria, era orientado pelas mesmas forças e que as suas patologias tinham as mesmas causas que as dos outros órgãos, tese determinante na desmistificação da anatomia do sistema reprodutor feminino, especialmente na afirmação de que este obedecia aos mesmos princípios fisiológicos que o resto do corpo, fosse este masculino ou feminino ${ }^{21}$. No que diz respeito a condições naturais, a mulher tem,

\footnotetext{
${ }^{16}$ Sobre a obra de Herófilo, veja-se o estudo essencial de VON STADEN, 1989.

${ }^{17}$ Gal. Sem. 2.1 (4.596K). Em De usu partium (4.193K), Galeno afirma que foi Herófilo quem utilizou pela primeira

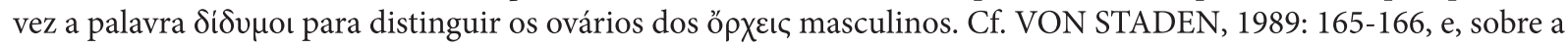
utilização deste vocábulo para designar os ovários, HERRERO INGELMO, 2002.

${ }^{18}$ Sobre a descoberta dos ovários e das trompas de Falópio por Herófilo, cf. VON STADEN, 1989: frg 61.

${ }^{19}$ VON STADEN, 1989: 168-169.

${ }^{20}$ Gynaikeia é o título que lhe é dado na $S u d a(\Sigma 852)$, mas o único manuscrito que transmite o texto inclui uma lista dos assuntos tratados em cada uma das secções, lista que designa como Pinax peri gynaikeion pathon (Lista sobre as doenças das mulheres). Seguimos para o texto de Sorano a edição de BURGUIÊRE et al., 2003 [1988].

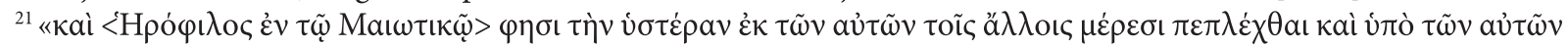

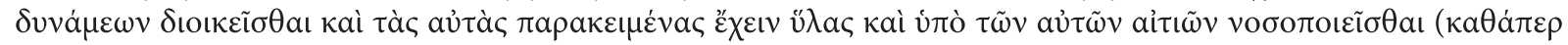

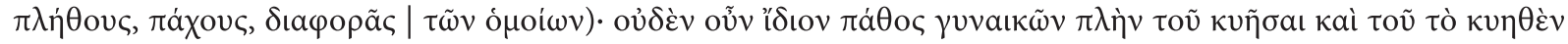

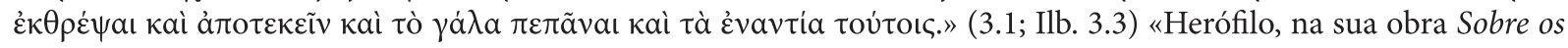
partos, afirma que o útero é formado pela mesma matéria que os outros órgãos, que é regulado pelas mesmas forças, que tem disponíveis as mesmas substâncias e que sofre doenças que têm as mesmas causas (por exemplo: quantidade, espessura e variação de substâncias semelhantes). Em consequência não há nenhuma condição na mulher que lhe seja peculiar, à excepção da concepção, da gravidez, do parto, da amamentação e de condições antagónicas a estas».
} 
de acordo com Sorano, condições específicas, como a concepção, a gravidez, o parto; mas nas condições não naturais, só no pormenor, isto é, nos sintomas e não no género de doença, é que as doenças das mulheres diferem das dos homens.

Tomamos como objecto de estudo sobre a diferenciação sexual em Galeno os livros XIV e XV do tratado De usu partium, em que se descrevem os órgãos reprodutores femininos e os masculinos. A estes órgãos criou-os a natureza com o único propósito de garantir a continuidade das espécies, enquanto outros órgãos têm como função garantir a vida, como o cérebro, o coração e o fígado, ou melhorar as condições de vida, como os olhos, os ouvidos ou o nariz. Galeno desenvolveu muitas das teorias dos seus predecessores. Beneficiando dos princípios da medicina hipocrática e dos estudos anatómicos de Herófilo e dos alexandrinos, fundamenta a sua análise da natureza feminina e dos órgãos genitais femininos e masculinos na obra aristotélica, criando com estas bases uma perspectiva sincrética, mas inovadora. Galeno eleva a outro nível o recurso aos comparativos para traçar a diferenciação dos sexos. Afirma:

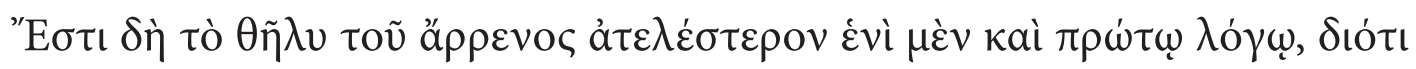

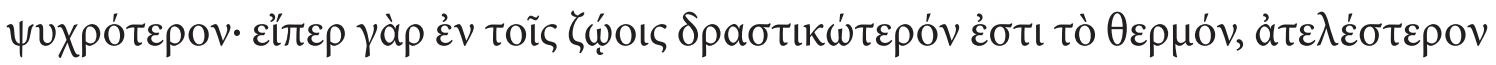

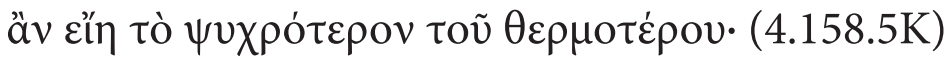

A fêmea é mais imperfeita do que o macho por uma razão principal: porque é mais fria, pois se entre os animais é mais activo o que é quente, o mais frio será mais imperfeito do que o mais quente.

Ou seja, a fêmea, porque é mais fria, é menos activa e menos perfeita. Atente-se nas formas do adjectivo teleios/ateles, que no texto galénico em análise são inúmeras, tanto no grau normal, como no comparativo ou no superlativo. E não são usados apenas para distinguir os sexos. O calor é um instrumento da natureza, o mais importante de acordo com Galeno. Por este motivo, os animais mais frios são menos perfeitos. Escreve:

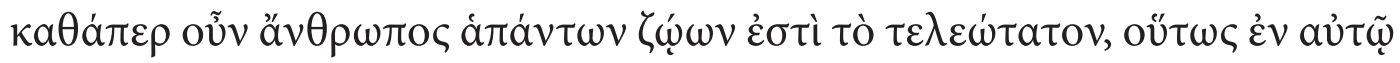

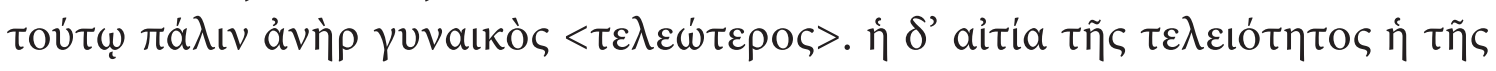

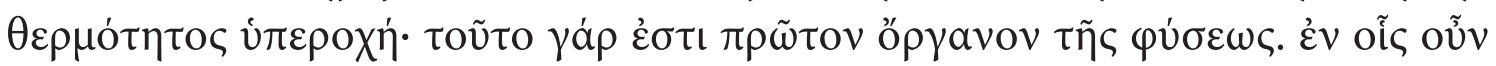

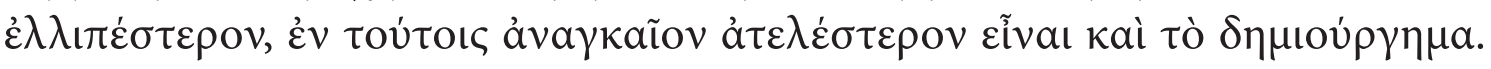

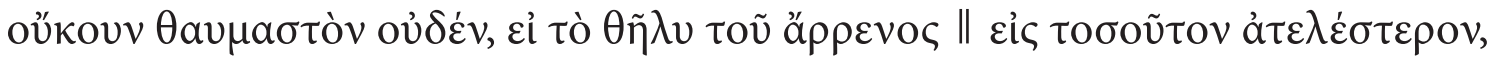

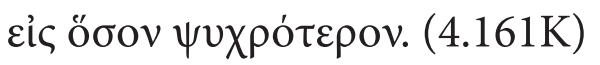

Pois como o ser humano é o mais perfeito de todos os animais, assim neste o homem é mais perfeito do que a mulher. A causa desta perfeição é a abundância de calor. Este é de facto o primeiro instrumento da natureza. Nos que não são quentes, 
a obra criada é por necessidade também mais imperfeita. Por isso, não é de admirar que a fêmea seja mais imperfeita do que o macho já que é mais fria.

Além da distinção entre o mais frio e o mais quente, o mais activo e o mais passivo, Galeno introduz a ideia de telos - que significa «fim», "acabamento», "termo» ou «perfeição». Este conceito é, na base, um conceito aristotélico, mas assume em Galeno uma importância maior. Note-se, todavia, que ao contrário das muitas elaborações que a oposição perfeito/imperfeito permite, Galeno é claro quando afirma que a natureza não teria feito metade da raça humana imperfeita e mutilada se não adviesse desta mutilação uma grande vantagem. A mulher é mais fria para não consumir todo o nutrimento, o que acontece nos homens, e para que sobre algo deste processo. É este resíduo sobrante, esta matéria, que permite que o embrião se forme e se desenvolva. É por este motivo que é útil que as fêmeas sejam mais frias do que os machos (4.163K). Mas esta frieza fez com que as partes genitais femininas fossem imperfeitas, uma vez que por falta de calor se mantiveram no interior do corpo humano.

Do De usu partium de Galeno (4.158-9K) ficou conhecida a analogia que aí se estabelece entre os órgãos sexuais femininos e os masculinos. Segundo Galeno, os órgãos genitais femininos são idênticos aos masculinos, mudando apenas a localização. $\mathrm{O}$ que os homens têm no exterior, as mulheres têm no interior por carência de calor intrínseco. Longe, porém, de se apresentar um modelo de sexo único - o masculino - e de se afirmar que o corpo das mulheres não é mais do que um desvio deste modelo que se configuraria como a norma, elabora-se uma imagem mental para explicar a diferença nos órgãos genitais. Fazendo corresponder órgão a órgão, cria-se um pretenso isomorfismo que está na base do modelo unívoco de Laqueur ${ }^{22}$. Note-se, porém, que a correspondência é apenas aparente, uma vez que a distinção entre os órgãos masculinos e os femininos é muito clara. Os ovários, por exemplo, que correspondem aos testículos, são menores, mais frios e produzem uma semente menos perfeita do que estes. Os vasos espermáticos masculinos são mais extensos do que os femininos precisamente para melhor elaborarem a semente. E, se o excerto citado tem sido interpretado como afirmação da misoginia do seu autor, parece, quando entendido em contexto, valorizar a diferença da mulher - ou melhor, da fêmea - como uma necessidade da natureza que nada deixa ao acaso. O vocabulário do espanto, da admiração e do respeito pelas obras da natureza repete-se como um refrão no De usu partium.

A mulher é entendida como um ser passivo, sedentário, parado e a sua vida e a sua saúde são condicionadas por órgãos e processos problemáticos e por uma natureza

\footnotetext{
${ }^{22} \mathrm{O}$ útero corresponderia ao escroto, os ovários aos testículos, o colo do útero ao pénis, etc. Realce-se, todavia, que o vocabulário associado à imaginação e à construção mental parecem indicar tratar-se de um exercício intelectual para descrever e visualizar órgãos interiores e, portanto, invisíveis a olho nu, tomando como ponto de partida orgãos exteriores e, por esta razão, visíveis e conhecidos. Para uma análise clara deste texto, cf. KING, 2013: 34ss.
} 
diferente da dos homens. Muitas das elaborações teóricas sobre a physis feminina fundamentam-se num princípio que se considera certo: que, por necessidade, as mulheres são diferentes dos homens. É o status quo de ordem social e cultural que justifica a diferença entre os sexos. Uma natureza, dois corpos? Sem querer impor divisões artificiais, eu proporia como modelo actuante nos tratados médicos antigos - predominante eventualmente mais em algumas épocas do que noutras - a equação: duas naturezas, dois corpos, duas existências.

\section{BIBLIOGRAFIA}

BURGUIÈRE, Paul; GOUREVITCH, Danielle; MALINAS, Yves (2003) - Soranos d'Éphèse. Maladies des femmes. Paris: Les Belles Lettres.

DEAN-JONES, Lesley (1994) - Women's bodies in classical Greek science. Oxford, New York: Oxford University Press.

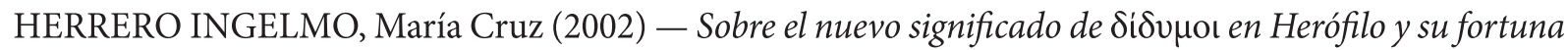
posterior. «Revista de Linguística y Filologia Clasica - Emerita», vol. 70, n. ${ }^{\circ} 1$. Espanha: Consejo Superior de Investigación Cientifica, p. 121-137.

KING, Helen (2013) - The one-sex body on trial: the classical and early modern evidence. Farnham and Burlington: VT.

MAYEW, Robert (2004) - The female in Aristotle's biology. Chicago: The University of Chicago Press.

NUTTON, Vivian (2004) - Ancient Medicine. London; New York: Routledge.

PARK, Katharine (2010) - Cadden, Laqueur and the «One-Sex Body». «Medieval Feminist Forum», vol. 46, n. ${ }^{\circ} 1$, p. $96-100$.

STOLBERG, Michael (2003) - A Woman Down to her Bones: The Anatomy of Sexual Difference in the Sixteenth and Early Seventeenth Centuries. «A Journal of the History of Science Society - Isis», vol. 94, n. ${ }^{\circ}$ 2. Chicago: The University of Chicago Press, p. 274-299.

VON STADEN, Heinrich (1989) - Herophilus: the art of medicine in early Alexandria: edition, translation, and essays. Cambridge; New York: Cambridge University Press. 